\title{
Knowledge of mental health legislation in Ghana: a case of the use of certificate of urgency in mental health care
}

Reindolf Anokye ${ }^{1^{*} \mathbb{D}}$, Enoch Acheampong ${ }^{1}$, Naomi Gyamfi ${ }^{1}$, Amy Budu-Ainooson ${ }^{2}$ and Ernest Appiah Kyei ${ }^{1}$

\begin{abstract}
Introduction: Mental illness can affect anyone irrespective of race, gender or personal characteristics. The study sought to investigate health workers' Knowledge on Mental Health Legislation in Ghana focusing on the Certificate of Urgency.

Methods: A descriptive study design was employed for this study. The study population included medical doctors, physician assistants, and nurses/midwives. A simple random sampling technique was used to select 384 respondents for the study. Data was collected through the use of semi-structured questionnaires.

Results: Respondents who were psychiatrists were 9.56 times more knowledgeable in the use of Certificate of Urgency than those in other specialties like primary care, obstetrics and gynaecology, surgery and internal medicine; adjusted odds ratio $(A O R)=9.56$ [95\% confidence interval $(C l)$ 1.57-65.2]. Respondents who had used the Certificate of Urgency before had 4.7 times more knowledge as compared to those who had not used it at all; adjusted odds ratio $(\mathrm{AOR})=4.77[95 \%$ confidence interval $(\mathrm{Cl}) 1.021-14.01]$.

Conclusion: Knowledge of Certificate of Urgency was generally low. Authorities of the various hospitals should organize regular in-service training to enlighten all healthcare workers on the legislation governing mental healthcare in Ghana.
\end{abstract}

Keywords: Health workers, Knowledge, Mental health legislation, Certificate of urgency

\section{Introduction}

Mental illness can affect anyone irrespective of race, gender or personal characteristics [1]. It is estimated that one in four persons worldwide is classified at some point in their life as persons with mental illness [2]. In the US, nearly $46 \%$ of the total population at some point in time qualify to be classified as persons with mental illness [3]. In Ghana, WHO estimates that approximately $13 \%$ of Ghanaians suffer from a mental disorder: of those, 3\% suffer from a severe mental disorder and the other $10 \%$ suffer from a moderate to mild mental disorder [4].

Many countries have passed Mental Health Acts. Examples include Sweden (Act 2003) in October 2005

\footnotetext{
*Correspondence: reindolfanokye@yahoo.com

${ }^{1}$ Centre for Disability and Rehabilitation Studies, Department of Community Health, Kwame Nkrumah University of Science and Technology, Kumasi, Ghana

Full list of author information is available at the end of the article
}

and India (Act, 1987) effected in 1993 which replaced the Indian Lunacy Act, 1912. In Ghana, the recent Mental Health Act (MHA) was passed in 2012. The Mental Health Act (MHA) seeks to protect persons with mental illness [5]. MHA is useful and covers not only the rights of patients and how to safeguard or protect individual rights but also include situations where one can be taken to a hospital against his or her will and occasions when one can be treated against his or her will [5].

One area that the MHA sought to encourage is the use of Certificate of Urgency [6]. In mental health care, the Certificate of Urgency is used for the involuntary treatment of persons with mental illness [7].

Even though there are legislative instruments that cater for persons with mental illness which are in the form of Mental Health Acts, there is continuous discrimination and stigma against persons with mental illness $[8,9]$. Also, many countries do not consider 
mental health care as a vital component of public health care [10].

According to Ghana's Mental Health Act (846) Section 48, clause 2 and 3 , when a registered medical practitioner examines a person with possible diagnosis of mental illness and meets the criteria for emergency care, the medical practitioner then issues a Certificate of Urgency to place the person under care, observation, and treatment. Also, any healthcare professional irrespective of their specialty may seek the assistance of the police to take a person to a health facility in a situation where the person is suspected to be suffering from a mental disorder for a Certificate of Urgency to be issued after examination by a medical practitioner.

Anecdotal evidence suggests that despite the provision of the Mental Health Act of Ghana, there seems to be less publicity about the use of the Certificate of Urgency as many citizens and even some health officers seem not to be aware of its existence.

In a study undertaken in Scotland which examined psychiatrists' knowledge of mental health legislation. The study findings revealed that knowledge of most basic definitions and fundamental areas was limited [11]. A study that was carried out to determine the levels of knowledge of Section 136, The Mental Health Act 1983 in the UK by Lynch et al. [12] also found a majority of respondents having low knowledge of the Act 1983. Passmore and Leung [13] study among psychiatrists found that half of the respondents did not know what certain provisions of the Human Rights Act stipulate. In Lovell et al. [14] study conducted among nurses holding powers in England, only $45 \%$ of the sample (164 nurses) knew the criteria set out in the Mental Health Act Code of Practice. Houlihan [15] study found that nurses' required more training on treatment without consent under the Mental Health Act 1983 in England.

Knowledge levels of mental health legislation among health workers' in Ghana is scanty. Therefore, the study sought to investigate health workers' knowledge on mental health legislation in Ghana focusing on the Certificate of Urgency. The study will bring to bear the extent to which healthcare workers are knowledgeable when it comes to the use of the Certificate of Urgency. This will enable stakeholders to assess the knowledge base of health officials in mental healthcare in order to plan ways to improve it. The study will expose the use of Certificate of Urgency in Ghana. This will enable readers to become fully aware of the functionality of the Certificate of Urgency and enlighten them on their role in improving mental healthcare.

\section{Methods}

A descriptive design was employed in this study and the design was selected based on the fact that descriptive research allows the researcher to only express what is happening on the field without any additions from the researcher's perspective. The researcher's duty in descriptive research is to only observe and present exactly the phenomenon of study [16]. Specifically, the health officer's use of Certificate of Urgency in mental healthcare was expressed as it existed on the field devoid of the investigator's opinion and sentiments.

The targeted population for the study was Medical Doctors, Physician Assistants, and Nurses who as part of their duties are engaged in providing treatment and referral services to persons with mental illness. The study population comprised of all health officials of 7 public hospitals in 3 regions (Central, Greater Accra, and Ashanti) of Ghana.

A multi-stage sampling technique was employed where three (3) regions were purposively selected due to the reason that the three psychiatric hospitals in the country are located in 2 of the regions (Central and Greater Accra) and the other being Ashanti has one of the largest hospitals in Ghana. After that, seven (7) hospitals were also purposively selected based on the availability of psychiatrists or mental health practitioners (Registered mental nurses, community mental health officers, and psychiatrists). These hospitals were selected in order to increase the probability of selecting a significant number of psychiatrists or mental health practitioners among other health workers. A simple random sampling technique was then used to select the respondents from the hospitals. The probability sampling was used in order to also include other health professionals who may not be psychiatrist but play other roles when it comes to mental health as in the case of midwives who play a significant role in the management of postpartum depression/postpartum psychosis.

Respondents were randomly selected by letting them pick a paper that was folded and had 'Yes' or 'No' written in it. Those who picked 'Yes' were selected till the minimum sample size was achieved. In this study, the minimum sample size was estimated using the formula of Cochran [17] which is recommended for studies where the total population is not known.

The formula is;

$$
n_{0}=\frac{z^{2} \times p(1-p)}{e^{2}} \text {. }
$$

The following values were used for estimating the sample size $-n_{0}$ : ?, $z^{2}$ : $95 \%$ confidence level (The value of $(1-\alpha)$ in standard normal distribution $z$-table, which is 
1.96 for $95 \%$ ), $p: 50 \%$ variability of the population (which is maximum), $e: 5 \%$ margin of error. Where, $n_{0}$ : sample size, which was estimated, $z^{2}$ : selected critical value of the desired level of confidence or risk, $p$ : estimated proportion of an attribute that is present in the population or maximum variability of the population, $e$ : the desired level of precision or margin of error.

The values were placed in the formula;

$$
n_{0}=\frac{(1.96)^{2} \times 0.5(1-0.5)}{(0.05)^{2}}=384.16
$$

The minimum sample size of 384 was obtained. Therefore, a sample of 384 was selected for the study. However, out of the estimated sample of 384 respondents, 5 exited at the early stages of the study and 379 respondents completed the study. Therefore the margin of error was $0.58 \%$.

Data was collected through the use of semi-structured questionnaires and were self-administered by respondents. A pre-test was conducted in two different regions to ascertain the potency of the sampling procedure and the viability of the research instruments. Cronbach's Alpha was used to test the viability of the questionnaires and the value of the Cronbach's Alpha was 0.62 (more than 0.5 and above are recommended values), the questionnaire was subsequently modified to achieve higher viability. This made the instrument more appropriate which improved data collection. Difficulties in interpreting information in the research instruments were corrected by simplifying the wording.

The investigators personally arranged for the administration of the research instruments after a prior visit that assisted in refining timings of distribution of questionnaires. The investigators agreed with the respondents when the research instruments were to be administered and the specific date of collecting the questionnaires. A period of one (1) week was allowed for the respondents to answer the questionnaire.

To render the study ethical, the right of self-determination, anonymity, confidentiality and informed consent were observed. Written and verbal permission was obtained to conduct the study in the hospital. Respondents were told the purpose of the study, the procedure that would be used to collect the data, and assured them that there were no potential risks or cost involved. Scientific sincerity is regarded as a very important ethical responsibility when conducting research. Therefore the researcher took the following ethical consideration in the process of collecting the data for the study. The respondents for the study were allowed to participate voluntarily in the research without been persuaded. The reason for the observance of this was that if they are not allowed to participate out of their own volition, they will give false information that will mar the objectives of the research. The respondents of the study were told the objectives of the study, the possible implication and effect of the research. As a result of this, the information given was based purely on informed consent. The confidentiality of the study was paramount and observed by the researcher. The data collected were managed and used in such a way that the identity of the respondents were protected and that no information can be directly traced or associated with any individual respondent. All references were duly acknowledged to prevent plagiarism.

Data cleaning was done which involved identification of incomplete or inaccurate responses and completed ones. After data cleaning, the data were coded and entered into the computer for analysis using the Statistical Package for Social Sciences (SPSS) version 20 and the excel spreadsheet. Results have been presented in percentages and frequencies through frequency tables and pie charts.

\section{Results \\ Demographic characteristics of respondents}

Table 1 indicates the demographic characteristics of the respondents for the study. The demographic variables of respondents studied covered age, gender, professional qualification, specialties and years of working experience. More than half of the respondents were females constituting 53\%. The highest age group among the respondents was between the age range $26-35$ years. Out of the total number of respondents, $88 \%$ were nurses/ midwives representing the largest professional group. With regard to the specialties of the respondents, $52 \%$ of respondents indicated primary care as their main specialty field while $4 \%$ of the respondents practiced psychiatry/mental healthcare. Over half $(53 \%)$ of the total number of respondents had between 1 and 5 years working experience with only $3 \%$ having 16 years and more working experience.

\section{Knowledge of Certificate of Urgency}

The knowledge of respondents on Certificate of Urgency was assessed to indicate their level of awareness on specific regulations guiding the use of Certificate of Urgency. From Table 2, close to half $(47 \%)$ of respondents were aware of the existence of Certificate of Urgency under the Mental Health Act. Less than half $(42 \%)$ of the total number of respondents indicated that a patient under Certificate of Urgency can be detained not exceeding $72 \mathrm{~h}$. Respondents who were aware of the specific regulation that "a person shall be received and detained in any other place of safe custody for a period not exceeding $48 \mathrm{~h}$ " were 127 representing $34 \%$ of the total number of respondents. Regarding their awareness of the existence 
Table 1 Demographic characteristic of respondents

\begin{tabular}{|c|c|c|}
\hline Demographic variables & $\begin{array}{l}\text { Frequency } \\
(\mathrm{n}=379)\end{array}$ & $\begin{array}{l}\text { Percentage } \\
\text { (\%) }\end{array}$ \\
\hline \multicolumn{3}{|l|}{ Gender } \\
\hline Female & 202 & 53 \\
\hline Male & 177 & 47 \\
\hline \multicolumn{3}{|l|}{ Age } \\
\hline $18-25$ & 122 & 32 \\
\hline $26-35$ & 173 & 46 \\
\hline $36-45$ & 65 & 17 \\
\hline $46-55$ & 10 & 3 \\
\hline 56 and above & 9 & 2 \\
\hline \multicolumn{3}{|l|}{ Professional qualification } \\
\hline Med. doctor & 16 & 4 \\
\hline Phy. assistants & 29 & 8 \\
\hline Nurse/midwife & 334 & 88 \\
\hline \multicolumn{3}{|l|}{ Specialties } \\
\hline Primary care & 198 & 52 \\
\hline Obstetrics and gynecology & 96 & 25 \\
\hline Surgery & 22 & 6 \\
\hline Psychiatry/mental health & 16 & 4 \\
\hline Internal medicine & 47 & 12 \\
\hline \multicolumn{3}{|l|}{ Years of work (years) } \\
\hline $1-5$ & 213 & 56 \\
\hline $6-10$ & 121 & 32 \\
\hline $11-15$ & 34 & 9 \\
\hline 16 years and above & 11 & 3 \\
\hline
\end{tabular}

Table 2 Knowledge of Certificate of Urgency

\begin{tabular}{lc}
\hline Variables & Frequency ( $\mathbf{n = 3 7 9 )} \%$ \\
\hline Awareness of Certificate of Urgency under mental health act \\
Yes & $179(47 \%)$ \\
No & $200(53 \%)$ \\
A patient under the Certificate of Urgency may be detained not \\
exceeding $72 \mathrm{~h}$ \\
Yes & $219(58 \%)$ \\
No & $160(42 \%)$ \\
A person shall be received and detained in any other place of safe \\
custody for a period not exceeding $48 \mathrm{~h}$ \\
Yes & $127(34 \%)$ \\
No & $255(66 \%)$ \\
The existence of any procedure in issuing the Certificate of Urgency \\
Yes & $213(56 \%)$ \\
No & $166(44 \%)$ \\
Where the Certificate of Urgency can be obtained \\
Any health facility & $41(11 \%)$ \\
Ministry of health office & $69(18 \%)$ \\
Ghana health service officers & $120(32 \%)$ \\
Psychiatric hospital & $49(13 \%)$ \\
Don't know & $100(26 \%)$ \\
\hline
\end{tabular}

of any procedure in issuing the Certificate of Urgency, the majority (56\%) indicated their awareness of existing proceedings in the issue of the Certificate of Urgency. Among the places where Certificate of Urgency could be obtained, Ghana Health Service were the commonest place mentioned by $32 \%$ of the respondents who were aware that Certificate of Urgency could be obtained from that end whilst $26 \%$ of the respondents were not aware of where the Certificate of Urgency could be obtained.

\section{Use of Certificate of Urgency}

Figure 1 illustrates respondents' utilization of Certificate of Urgency in their field of practice. The majority (73\%) of the respondents had never used Certificate of Urgency in their field of practice with less than half (27\%) of the respondents indicating the usage of Certificate of Urgency.

\section{Instance the hospital can issue the Certificate of Urgency}

From Fig. 2, it can be observed that $37 \%$ of the respondents stated that a Certificate of Urgency can be issued when a patient is showing signs of having a mental illness. Other notable cases mentioned by respondents where Certificate of Urgency could be used includes when there is the need for urgent treatment (29\%), the need to refer the patient to another facility (18\%) and when a patient is brought to the facility by police officer (16\%).

\section{Association between demographic characteristics, the use of Certificate of Urgency and Knowledge of Certificate of Urgency}

Table 3 summarizes the result of the univariate and multivariate analysis of the association between demographic characteristics as well as the use of Certificate of Urgency

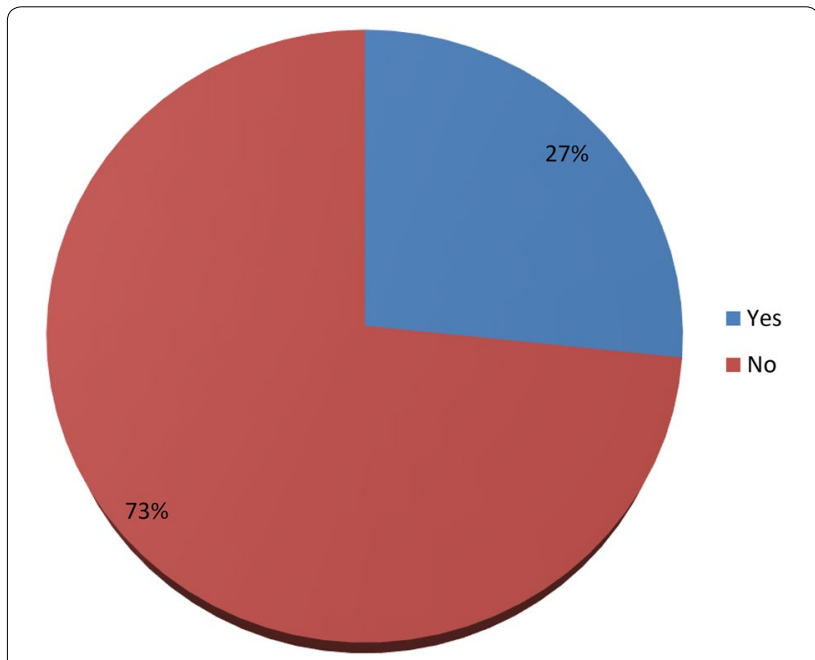

Fig. 1 Use of Certificate of Urgency 


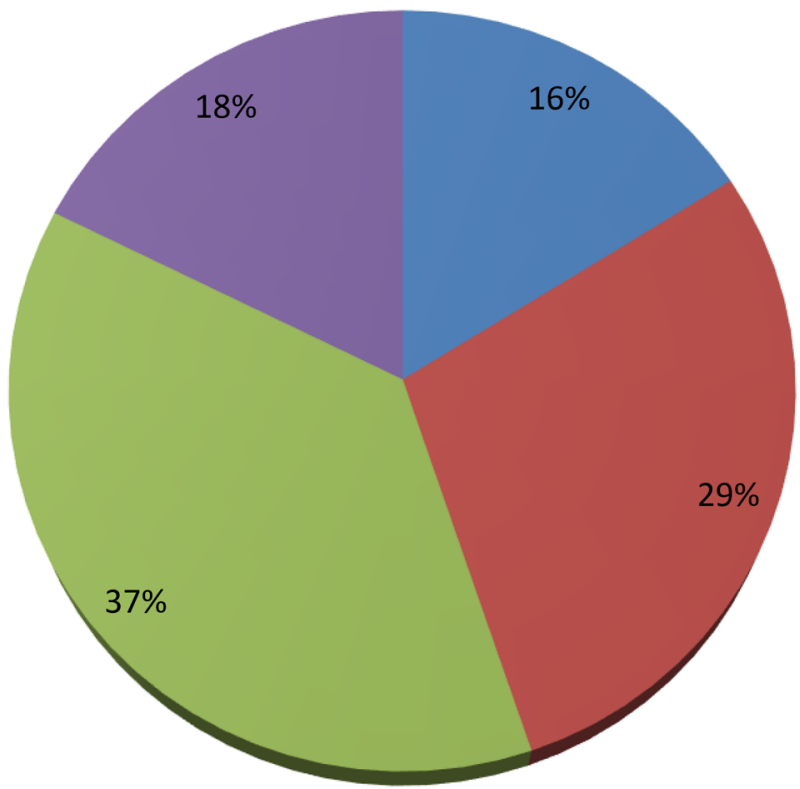

When a patient was brought to the facility by Police officer

The need for urgent treatment

When a patient is showing signs of having mental illness

The need to refer the patient to another facility

Fig. 2 Instance the hospital can issue the Certificate of Urgency

and knowledge of Certificate of Urgency. In both the univariate analysis and the multivariate analysis, specialty of the health workers and the use of the Certificate of Urgency had an association with having adequate knowledge of the Certificate of Urgency. Respondents who were psychiatrists were 9.56 times more knowledgeable when it comes to issuance and other information related to the Certificate of Urgency than those in other specialties like primary care, obstetrics and gynaecology, surgery and internal medicine; adjusted odds ratio $(\mathrm{AOR})=9.56$ [95\% confidence interval (CI) 1.57-65.2]. Respondents who had used the Certificate of Urgency before had 4.7 times more knowledge as compared to those who had not used it at all; adjusted odds ratio (AOR) $=4.77[95 \%$ confidence interval (CI) 1.021-14.01].

\section{Discussions}

A study by Humphreys [11] to assess psychiatrists' knowledge of mental health legislation indicated inadequate knowledge on the foundational and essential areas within the mental health legislation. A similar finding was evidenced in this study as health workers were not adequately aware of certain aspects of the Mental Health Act and specific regulations guiding the issuance and usage of Certificate of Urgency. This may be as a result of the lack of training of health professionals in mental health legislation in the provision of mental healthcare. Respondents who were psychiatrists had 9 times more adequate knowledge when it comes to the issuance and related information on Certificate of Urgency than those in other specialties like primary care, obstetrics and gynaecology, surgery and internal medicine. It is important for the authorities to increase their efforts in organizing training programmes to educate and enlighten all health workers within their healthcare facilities on mental health legislation in the provision of mental healthcare. This has the potential of increasing the knowledge of healthcare providers on mental health issues which will eventually improve their performance. This is important because it has been reported in Nigeria that the provision of in-service training through the development of strategies for the promotion, prevention, management, treatment and rehabilitation of mental and neurological disorders has improved the performance of healthcare professionals when it comes to management of mental illness [18].

Another study undertaken by Lynch et al. [12] on the levels of knowledge of Section 136 of the Mental Health Act 1983 in the UK found different results compared to what was found in this study. In Lynch et al. [12] study, 179 questionnaires were administered to 30 senior doctors, 24 senior house officers, 33 senior nurses and 92 police officers. Out of these respondents, $10 \%$ of the health workers who were Accident and Emergency practitioners and $23 \%$ of the police had been formally trained on the Mental Health Act 1983. The discrepancies between these two studies could arise from the nature of participants and health workers specialties included in the various studies. In this study, police officers were not included and participants had no specialty of accident 
Table 3 Odds ratio with $95 \%$ confidence interval for association between demographic characteristics as well as the use of Certificate of Urgency and Knowledge of Certificate of Urgency

\begin{tabular}{|c|c|c|c|c|c|c|}
\hline \multirow[t]{2}{*}{ Variables } & \multicolumn{2}{|c|}{ Knowledge of Certificate of Urgency } & \multicolumn{2}{|l|}{ Univariate } & \multicolumn{2}{|l|}{ Multivariate $^{a}$} \\
\hline & Adequate (n) & Inadequate (n) & OR $(95 \% \mathrm{Cl})$ & P-value & AOR $(95 \% \mathrm{Cl})$ & P-value \\
\hline \multicolumn{7}{|l|}{ Gender } \\
\hline Female & 72 & 130 & $1.10(0.48-2.48)$ & 0.797 & $0.85(0.19-3.09)$ & 0.698 \\
\hline Male & 68 & 109 & 1.00 & & 1.00 & \\
\hline \multicolumn{7}{|c|}{ Professional qualification } \\
\hline Med. doctor & 14 & 2 & $1.02(0.44-2.35)$ & 0.838 & $1.62(0.41-5.66)$ & 0.529 \\
\hline Phy. assistance & 15 & 14 & 1.00 & & 1.00 & \\
\hline Nurse & 111 & 223 & $1.14(0.32-4.01)$ & 0.912 & $2.00(0.17-25.05)$ & 0.636 \\
\hline \multicolumn{7}{|l|}{ Specialties } \\
\hline Primary care & 68 & 130 & 1.00 & & 1.00 & \\
\hline Obst. and gynecol. & 50 & 46 & 2.01 & 0.139 & $1.21(0.28-6.27)$ & 0.706 \\
\hline Surgery & 6 & 16 & 1.00 & & & \\
\hline Psychiatry & 12 & 4 & $12.5(3.54-45.49)$ & $<0.001$ & $9.56(1.57-65.2)$ & 0.014 \\
\hline Internal medicine & 4 & 43 & $6.33(0.08-1.56)$ & 0.112 & $0.44(0.08-2.46)$ & 0.255 \\
\hline \multicolumn{7}{|l|}{ Years of work (years) } \\
\hline $1-5$ & 73 & 140 & 1.00 & & 1.00 & \\
\hline $6-10$ & 42 & 79 & $0.89(0.41-3.02)$ & 0.797 & $1.29(0.35-4.81)$ & 0.122 \\
\hline $11-15$ & 22 & 12 & $2.86(1.13-20.28)$ & 0.121 & $1.31(0.04-2.19)$ & 0.211 \\
\hline 16 years and above & 3 & 8 & 1.00 & & 1.00 & \\
\hline \multicolumn{7}{|c|}{ Use of the Certificate of Urgency } \\
\hline Yes & 81 & 20 & $8.21(3.12-20.18)$ & $<0.001$ & $4.77(1.021-14.01)$ & 0.044 \\
\hline No & 59 & 219 & 1.00 & & 1.00 & \\
\hline
\end{tabular}

$O R$ odds ratio, $\mathrm{Cl}$ confidence interval, $A O R$ adjusted odds ratio

a Mutually adjusted

and emergency staff. A further investigation could be done to assess the knowledge of police officers who may have the power to hold up suspected persons with mental illness in public places and keep them safe.

The Mental Health Act of Ghana sets out established guidelines for the treatment of mental disorders and in the issuing of the Certificate of Urgency. The study found that more than half of the respondents (56\%) knew the existing procedures in issuing the Certificate of Urgency. However, less than half of the sample (45\%) of nurses in England in a study conducted by Lovell et al. [14]. was cognizant of the specific principles set out in the Mental Health Act Code of Practice. This may be as a result of the inclusion of other health professionals in this study who may be conversant with the procedure in issuing the Certificate of Urgency as compared to the use of the only nurse in the study in England.

\section{Strengths of the study}

The study has provided vital information on the Mental Health Act that will support mental healthcare in Ghana. The sample size was large enough and healthcare professionals from different specialties were included in the study.

\section{Limitations of the study}

The scope of the study was limited to southern Ghana, therefore, ignoring the other mental health practitioners and health workers in the northern part of the country. The Procedure for the issuance of a Certificate of Urgency also involves police officers and family members of persons with mental illness'. However, they were not included in the study due to the focus on health workers. Whilst there may be limitations inherent in the study and approaches used, these by no means compromise the results reported.

\section{Conclusion}

The knowledge of respondents on Certificate of Urgency was assessed based on the findings, it can be concluded that knowledge on the Certificate of Urgency and its utilization among health workers was generally low. Health workers in psychiatry, however, were more knowledgeable when it comes to the use of Certificate of Urgency 
than those in other specialties as they have received specific training on mental healthcare.

\section{Recommendation}

It is recommended that the authorities of the various hospitals should organize regular in-service training programmes, refresher courses and workshops to educate and enlighten all health workers within their healthcare facilities on mental health legislation in the provision of mental healthcare.

Again, the Ministry of Education should collaborate with the Ghana Health Service to revise the curriculum of the various health training institutions across the country to enhance training on mental health legislation.

\section{Abbreviations}

MHA: Mental Health Act; AOR: adjusted odds ratio; OR: odds ratio; $\mathrm{Cl}$ : confidence interval; SPSS: Statistical Package for Social Sciences.

\section{Authors' contributions}

The secondary data compilation, data analysis and collection, and interpretation were done by the first author (RA). The second, third, fourth and fifth authors revised the manuscript thoroughly with their individual expertise. In the analysis of data, all authors played a significant part as well as in designing and preparing the manuscript. Proofreading and the final approval process was also shared accordingly among all authors and all authors have agreed to its submission for publication. All authors read and approved the final manuscript.

\section{Author details}

${ }^{1}$ Centre for Disability and Rehabilitation Studies, Department of Community Health, Kwame Nkrumah University of Science and Technology, Kumasi, Ghana. ${ }^{2}$ Department of Health Education and Promotion, School of Public Health, Kwame Nkrumah University of Science and Technology, Kumasi, Ghana.

\section{Acknowledgements}

Our gratitude goes out to the management and staff of the selected hospitals, as well as the regional health directorate officials in Central, Greater Accra and Ashanti region of Ghana for their support. Further thanks to all whose works on mental health helped in putting this work together.

\section{Competing interests}

The authors declare that they have no competing interests.

\section{Availability of data and materials}

A complete document of this study and its results can be found at the Library of the School of Medical Sciences, KNUST, Kumasi.

\section{Consent to publish}

Not applicable.

\section{Ethics approval and consent to participate}

Letter of introduction was sent to the administration unit of the selected hospital to seek permission to carry out research in their institutions. The study was approved by the committee on Human Research Publication and ethics at Kwame Nkrumah University of Science and Technology, Kumasi-Ghana.

Written and verbal permission was obtained to conduct the study in the hospital. An introductory letter was sent to the various departments in the hospitals for approval before data collection commenced. The respondent of the study was told the objectives of the study, the possible implication and effect of the research. Verbal consent was obtained from participants before they participated in the study. The data collected had no information that could directly be traced to or associated with any individual respondent by removing identifiers such as names, and contact details of respondents. Participation was purely voluntary and any participant who wanted to withdraw was allowed. Confidentiality was guaranteed before administering the questionnaires.

\section{Funding}

No external funding was received for the purpose of this study. All cost related to this research was covered by the researchers themselves.

\section{Publisher's Note}

Springer Nature remains neutral with regard to jurisdictional claims in published maps and institutional affiliations.

Received: 10 May 2018 Accepted: 16 June 2018

Published online: 28 June 2018

\section{References}

1. Herrman $\mathrm{H}$. The need for mental health promotion. Aust NZ J Psychiatry. 2001;35(6):709-15.

2. World Health Organization. The World Health Report 2001: mental health: new understanding, new hope. Geneva: World Health Organization; 2001.

3. Kessler RC, Demler O, Frank RG, Olfson M, Pincus HA, Walters EE, Wang P, Wells KB, Zaslavsky AM. Prevalence and treatment of mental disorders, 1990 to 2003. N Engl J Med. 2005;352(24):2515-23.

4. WHO. Ghana country summary. 2007 http://www.who.int/mental/healt h/policy/country/GhanaCoutrySummary. Accessed 12 Apr 2018.

5. Marriott S, Bernard A, Paul L, Yvonne W, Richard DS. Research into the Mental Health Act: a qualitative study of the views of those using or affected by it. J Ment Health. 2001;10(1):33-9.

6. Ame R, Mfoafo-M'Carthy M. Mental health law in Ghana: the rights of children with mental disorders. Soc Develop Issues. 2016;38(1):1-4.

7. Doku VC, Wusu-Takyi A, Awakame J. Implementing the Mental Health Act in Ghana: any challenges ahead? Ghana Med J. 2012;46(4):241.

8. Math SB, Murthy P, Chandrashekar CR. Mental health act (1987): need for a paradigm shift from custodial to community care. Indian J Med Res. 2011;133(3):246.

9. Teh JL, King D, Watson B, Liu S. Self-stigma, perceived stigma, and help-seeking communication in people with mental illness. PORTAL J Multidiscipl Int Stud. 2014:3:11.

10. Math SB, Nagaraja D. Mental health legislation: an Indian perspective. In: Nagaraja D, Murthy P, editors. Mental Health and Human Rights. Bangalore: National Institute of Mental Health and Neuro Sciences (Deemed University); 2008. p. 49-68.

11. Humphreys $C$. Responding to the individual trauma of domestic violence: challenges for mental health professionals. Soc Work Ment Health. 2008;7(1-3):186-203.

12. Lynch RM, Simpson M, Higson M, Grout P. Section 136, The Mental Health Act 1983; levels of knowledge among accident and emergency doctors, senior nurses, and police constables. Emerg Med J. 2002;19(4):295-300.

13. Passmore K, Leung WC. Psychiatrists' knowledge of the Human Rights Act and its relevance to mental health practice: a questionnaire survey. Med Sci Law. 2003:43(2):136-40.

14. Lovell K, Gray R, Thomas B. The use of nurses' holding power in a large psychiatric hospital. Nurs Stand (through 2013). 1998;12(43):40.

15. Houlihan GD. The powers and duties of psychiatric nurses under the Mental Health Act 1983: a review of the statutory provisions in England and Wales. J Psychiatr Ment Health Nurs. 2005;12(3):317-24.

16. Holloway I, Galvin K. Qualitative research in nursing and healthcare. New York: Wiley; 2016

17. Cochran WG. Sampling Techniques, New York, 1953. Grebenik and CA Moser: Statistical Surveys E; 1963.

18. World Health Organization. WHO-AIMS report on mental health system in Nigeria. Nigeria: Ministry of Health; 2006. 